\title{
The Valuation of IPOs by Investment Banks and the Stock Market: Empirical Evidence (*)
}

This version: 11 January 2002

\author{
Marc DELOOF \\ University of Antwerp \\ Wouter DE MAESENEIRE \\ Ghent University \\ Koen INGHELBRECHT \\ Ghent University
}

Correspondence to: Marc Deloof, Faculty of Applied Economics UFSIA-RUCA, University of Antwerp, Prinsstraat 13, 2000 Antwerp BELGIUM; E-mail: Marc.Deloof@ua.ac.be; Tel: +32-3-220 41 69; Fax: +32-3-220 4799

(*) We are grateful to An Buysschaert, Marc De Ceuster, Nancy Huyghebaert, Marc Jegers, Sophie Manigart, Ilse Verschueren, and participants at the 2001 EIASM International Workshop on Capital Market Research for helpful comments and suggestions. The usual disclaimer applies. 


\title{
The Valuation of IPOs by Investment Banks and the Stock Market:
}

\section{Empirical Evidence}

\begin{abstract}
In this paper, pre-IPO value estimations by the lead underwriting investment bank of Belgian IPO stocks are compared to the offer price and the stock price in the first month of listing. The valuation methods used by the lead underwriter and the estimated values are often discussed in Belgian IPO-prospectuses. For 33 IPOs in the 1993-2000 period, we find that in all cases the lead underwriter uses several methods to estimate stock value. Discounted free cash flow, which is used to price all IPOs in the sample, is the most popular valuation method. The IPO offer price is mainly driven by the dividend discount model if applied. However, we find that the dividend discount model is not better in predicting the stock price than other valuation models. Moreover, our results suggest that the dividend discount model tends to underestimate value, while discounted free cash flow produces unbiased results. This indicates that underwriters consciously underprice the IPO by relying on a valuation method that tends to underestimate value. We also find that price/earnings and price/cash flow multiples using forecasted earnings and cash flows for the year after the IPO lead to more accurate valuations than multiples using forecasted earnings and cash flows for the IPO-year. Finally, our results indicate that the offer price is closer to the stock price after listing than individual valuation estimates, although the differences are not statistically significant.
\end{abstract}

JEL code: G24, G30, G31 


\section{Introduction}

A firm conducting an initial public offering (IPO) needs to have its stock valued before the IPO, in order to determine a price range within which the stock will be offered to the public. There are several methods available for stock valuation. The most widely used valuation approaches are the dividend discount model (DDM), the discounted free cash flow (DFCF) method, and valuation approaches that rely on comparing the firm to firms in similar industries and firms involved in similar transactions.

Several studies examine the accuracy of these valuation models. Alford (1992) tests the accuracy of the price-earnings $(\mathrm{P} / \mathrm{E})$ valuation model for US when comparable firms are selected on the basis of industry, firm size and earnings growth, by comparing actual stock prices to predicted stock prices. His results show that selecting comparable firms by industry is relatively effective. Kaplan and Ruback (1995) examine the discounted cash flow and comparable firm approaches in the context of highly leveraged transactions, and conclude that both approaches are useful and reliable. According to Kaplan and Ruback, discounted cash flow valuation methods perform at least as well as valuation approaches using companies in similar industries and companies involved in similar transactions. Gilson et al. (2000) find that, for firms that reorganize in bankruptcy, the discounted cash flow and comparable firm approaches have about the same degree of accuracy and lead to estimates that are generally unbiased but not very precise.

Two studies investigate specifically the valuation of IPOs. Kim and Ritter (1999) value a sample of IPOs in the US using P/E and price-to-book comparables, and find that these methods lead to very imprecise valuations when historical accounting numbers are used. 
However, when forecasted earnings are used, the accuracy of the valuation improves substantially. Berkman et al. (2000), who value 45 newly listed firms IPOs in New Zealand, conclude that the best discounted cash flow and P/E valuations have similar accuracy.

An important feature of all these studies is that they use ex post value estimations by the researcher(s) to test the accuracy of valuation methods. In Belgium, pre-IPO value estimates of Belgian IPOs by the lead underwriting investment bank are often published in the IPOprospectus. This allows us to examine the accuracy of the valuation models as used by investment banks. It can be expected that the accuracy of ex ante valuation by investment banks will differ from the valuation accuracy measured by academics, for several reasons. Value estimates by investment banks may be less accurate because academics are more objective than investment banks, who may be tempted to report valuations that justify a high price, for instance by choosing comparables with high multiples. On the other hand, value estimates by investment banks may be more accurate than value estimates by academics because investment banks have more information for valuation available. Moreover, as the stock market is pricing perceptions of the future and not the future itself, the value estimates by lead underwriters and the offer price, which to some extent will be based on these value estimates, may influence these perceptions and therefore the stock price. However, in an efficient market mispricing by underwriters should not affect market valuation.

We are not aware of any other papers that use 'real world' estimations to investigate the different valuation approaches ${ }^{1}$. In this paper, we investigate the valuation of 33 IPOs on the Brussels Stock Exchange (BXS) in the 1993-2000 period. Most IPOs on the BXS are mature

\footnotetext{
${ }^{1}$ DeAngelo (1990) decribes the use of different valuation approaches by a limited number of investment bankers to evaluate the fairness of management buyouts in 1988, but does not investigate the accuracy of these valuations.
} 
firms, that should be relatively easy to value. First, we want to know what valuation methods investment bankers use, and on which methods they rely most to determine the IPO offer price. We find that for each IPO several valuation methods are used, of which DFCF is the most popular: the DFCF model is used to value all IPOs in the sample. However, the offer price seems to be mainly driven by the DDM if applied. Next, we investigate the accuracy of different valuation methods by comparing the pre-IPO valuations to the average stock price in the first month of listing and to the stock price on post-IPO days $+10,+20$ and +30 . We find that the DDM is neither better nor worse in predicting market value than other valuation models. Moreover, our results suggest that the dividend discount model tends to underestimate value, while discounted free cash flow produces unbiased results. This indicates that underwriters consciously underprice the IPO by relying on a valuation method that tends to underestimate value. We also find that $\mathrm{P} / \mathrm{E}$ and price/cash flow $(\mathrm{P} / \mathrm{CF})$ multiples using forecasted earnings and cash flows in the IPO-year lead to less accurate valuations than multiples using forecasted earnings and cash flows in the year after the IPO, which is consistent with results of Kim and Ritter (1999). Finally, we compare the offer price and estimates of individual valuation methods to the post-IPO stock market price. We expect that lead underwriters use other valuable information besides value estimates to determine the offer price. Consistent with this hypothesis, our results indicate that the offer price is closer to the stock market price than individual value estimates. However, these results are not statistically significant.

The remainder of the paper is organized as follows. The next section describes the sample along with some statistics and discusses the methodology. In section 3 valuations are analyzed and compared to the IPO offer price and the average stock market price in the first month of listing. Section 4 presents some conclusions. 


\section{Sample and methodology}

Our sample includes all 33 IPOs of non-financial firms on the BXS from January 1993 to April 2000. For IPOs before 1993, there is insufficient information available on value estimates. Table I shows that these IPOs are active in a wide range of industries, including both 'high tech' industries and industries that do not rely on sophisticated technologies.

\footnotetext{
*** Table I about here ***
}

Table II presents some descriptive statistics. The median firm offers about one third of the number of post-IPO shares: in general, the initial owner retains control over the firm (the one share - one vote rule applies in Belgian corporate law). The initial returns, which are calculated as [average price in the first month of listing / offer price] - 1, show that for most IPOs there is substantial underpricing: the median initial return is $+10.3 \%$, and the mean initial return is $+18.9 \%$.

\footnotetext{
*** Table II about here ***
}

For most IPOs, at least a part of the shares are sold by existing shareholders: 8 firms offer only existing shares; 21 firms offer both existing and new shares; only 3 firms do not offer existing shares ${ }^{2}$. These findings are consistent with evidence from other European countries that a major motivation for European firms to go public is to allow the controlling shareholder to divest from the firm (see Pagano et al (1998) and Rydqvist and Högholm (1995)). 
All lead underwriters are Belgian banks, with the exception of ABN Amro Rothschild, which is co-lead underwriter of 2 IPOs $^{3}$. How do these lead underwriters value the firm? Table III contains the valuation methods used to value the 33 IPOs, and the number of cases in which they are applied. Some IPO prospectuses mention the use of a valuation method for which no estimation result is given. For these IPOs no comparison can be made for those particular valuation methods. All cases in which the use of a valuation method is mentioned in the prospectus are included in Table III. All lead underwriters mention only the use of generally accepted valuation methods and seem to avoid eccentric valuation methods as the ones described by Fernandez (2001). DFCF is the most popular method: it is used to value all IPOs. DDM is used for 23 IPOs, and a multiples approach is used to value 31 IPOs. All underwriters use at least 2 different valuation methods. $\mathrm{P} / \mathrm{E}$ and $\mathrm{P} / \mathrm{CF}$ are the most popular multiples approaches: P/E is applied for 30 IPOs and P/CF is applied for 19 IPOs. Other multiple approaches used are EnterpriseValue/EBITDA (6x), EnterpriseValue/EBIT (2x), EnterpriseValue/Sales (3x), Price/Book (1x), Dividend yield (2x) and P/E-to-Growth (1x).

*** Table III about here $* * *$

A problem with using multiples to value Belgian IPOs is that the number of firms listed on the BXS is limited. At the end of 1999 only 144 firms were listed, many of which are financial institutions and holding companies. It is therefore often difficult to find a sufficient number of comparable firms. In several cases, the underwriter compares the IPO to the BXS,

\footnotetext{
${ }^{2}$ For 1 observation we did not have sufficient information on the type of shares offered.

${ }^{3}$ Other (co-)lead underwriters are Generale Bank/Fortis Bank (13 IPOs), Bank Brussel Lambert (9 IPOs), KBC Securities (7 IPOs), Petercam (6 IPOs), Paribas/Artesia Bank (5 IPOs), Bank De Groof (4 IPOs), Lessius (1 IPO) and Delen \& Co (1 IPO).
} 
as well as to a peer group of firms, in order to estimate value. In some cases, value is also estimated using the average $\mathrm{P} / \mathrm{E}$ or $\mathrm{P} / \mathrm{CF}$ of growth shares on the $\mathrm{BXS}$. Table III shows that the $\mathrm{P} / \mathrm{E}$ of the $\mathrm{BXS}$ is used to value 14 IPOs, while the P/CF of the BXS is used for 9 IPOs. In one case, valuation is based on the average Enterprise Value/Sales ratio of the BXS. The P/E $(3 \mathrm{x})$ and the $\mathrm{P} / \mathrm{CF}(2 \mathrm{x})$ of BXS growth shares is used in only a very limited number of cases.

Multiples can be based on historical earnings or cash flows, but also on forecasted earnings and cash flows. Most multiples used in our sample are based on current year's forecasted earnings and cash flow (year 0) or next year's forecasted earnings or cash flow (year +1$)$. In a limited number of cases the underwriter also uses historical earnings and cash flow in the year before the IPO (year -1) and/or the forecasted earnings and cash flow for the second post-IPO year $($ year +2$)$. This leads to a wide range of multiples used by investment banks, along three dimensions: [1] type of multiple (P/E, P/CF, Price/book ..), [2] the firms to which the IPO is compared (peer group, all shares on the BXS, growth shares on the BXS), and [3] the timing of the multiple (years $-1,0,+1,+2$ ). In the remainder of the paper, we will investigate the estimations of the most frequently used multiples: $\mathrm{P} / \mathrm{E}$ and $\mathrm{P} / \mathrm{CF}$, for a peer group and for the $\mathrm{BXS}$, in years 0 and +1 . When we compare estimated values to market values, we will also present results for the 'best multiple'. This is the multiple for which the estimated value is closest to the offer price. We assume that the underwriter considers this to be the best multiple.

Valuation errors are computed as the natural $\log$ of the ratio of the estimated value either to the offer price or to the market value. We use three different measures of the accuracy of valuation methods which are commonly used in the literature on the quality of valuation methods: the percentage of valuation errors within $15 \%$, mean absolute valuation errors and 
mean squared valuation errors ${ }^{4}$. The mean absolute error assumes that the cost of valuation errors increases linearly, while the mean squared error assumes that the cost increases are quadratic.

\section{Results}

\section{A. On which method(s) do lead underwriters rely most to set the IPO offer price?}

We first investigate the relation between the IPO offer price and the results of the different value estimates by the lead underwriter. We want to find out on which valuation method(s) lead underwriters rely most to set the offer price. For this part of the analysis, we have one missing observation, for which we do not have information on the offer price. Table IV presents results for DFCF, DDM and the most commonly used multiple approaches: P/E and $\mathrm{P} / \mathrm{CF}$ based on a peer group and the BXS, calculated for year 0 and year +1 (these multiples are consistently closer to the offer price than the multiples for which no results are presented).

\section{*** Table IV about here $* * *$}

The median error for DFCF is 9.7\%: lead underwriters set the offer price significantly lower than the value estimates based on DFCF ( $p$-value of the Wilcoxon signed rank test is less than $0.1 \%$ ). The median error for DDM on the other hand is close to zero and not significant. The median errors for estimates based on multiples vary widely: they range from $-14.3 \%$ to

\footnotetext{
${ }^{4}$ See e.g. Kaplan and Ruback (1995), Kim and Ritter (1998) and Gilson et al. (2000). Some of these papers also report regression results. We do not use regression analysis in this paper because of the small size of our sample.
} 
$+12.5 \%$. These results provide a first indication that the lead underwriters rely primarily on DDM to determine the offer price.

We measure the degree of central tendency of value estimates towards the offer price by the percentage of differences within $15 \%$, mean absolute errors and mean squared errors. For 26 out of 32 IPOs ( $81 \%$ of the sample), the estimates based on DFCF are within $15 \%$ of the offer price. However, the offer price seems to be driven by DDM if applied: for 20 out of 22 IPOs (91\%) for which a DDM value is estimated, the estimate is within $15 \%$ of the offer price. For the multiples estimates, the percentages within $15 \%$ are much lower than for DFCF and DDM. An exception are the estimates using the forecasted P/CF of the BXS in year +1 ( 5 out of 6 IPOs are within 15\%), but this result is based on a very limited number of observations.

A comparison of the mean absolute and squared error of the different valuation methods leads to the same conclusions as the comparison based on the percentage within $15 \%$. A t-test of differences in the mean absolute error reveals that the mean absolute error of DDM estimates is significantly smaller than the mean absolute error of DFCF estimates $(t=2.54)$ and the mean absolute error $\mathrm{P} / \mathrm{E}$ peer group estimates in year $+1(\mathrm{t}=2.50)$, the most frequently used multiple estimation method. The mean absolute errors of DFCF and P/E peer group (year +1$)$ estimates are not significantly different $(t=0.65)$.

It therefore seems that when it comes to determining the IPO offer price, investment banks generally use a wide range of valuation methods, but still prefer to rely mostly on the good old DDM. Another interesting finding in Table IV is that the multiples valuations for year +1 
are consistently closer to the offer price than the multiples valuations for the IPO year 0: investment banks rely more on forecasted future multiples than on current multiples 5 .

Some valuation methods will be more appropriate to use than others. The underwriter has to choose which methods are appropriate and which are not. The results in Table IV may be influenced by this choice. For example, the difference between DFCF and DDM might be caused by the 10 IPOs for which DFCF was used but DDM was not. For the 22 IPOs for which both methods were used, the DFCF estimates might then be much closer to the offer price than the results in Table IV suggest. We therefore also investigate the relation between the IPO offer price and different value estimates by a pairwise comparison of valuation methods, for those IPOs that are valued with both methods. The results are presented in Table V. DFCF, DDM and P/E based on a peer group for year +1 are compared pairwise. We concentrate on the $\mathrm{P} / \mathrm{E}$ based on a peer group for year +1 because our performance measures indicate that this multiple is the one closest to the offer price. Moreover, $\mathrm{P} / \mathrm{E}$ based on a peer group is the most commonly used multiple. We also compare $\mathrm{P} / \mathrm{E}$ based on a peer group in year 0 and year +1 . All results in Table $V$ confirm those in Table IV.

*** Table $\mathrm{V}$ about here $* * *$

The value estimates by the lead underwriter are first used to determine minimum and maximum offer prices. The final offer price is set in a later stage of the IPO pricing, and will include information that was not available when the minimum and maximum prices were set. Following Kim and Ritter (1999), we therefore also compare estimated values to a

\footnotetext{
${ }^{5}$ The t-value of a t-test of differences in the mean absolute error between $\mathrm{P} / \mathrm{E}$ peer group (year 0 ) and $\mathrm{P} / \mathrm{E}$ peer group (year +1 ) is 2.53
} 
preliminary offer price, defined as the midpoint of the minimum and maximum offer prices. The results, which are presented in Table VI, show that the preliminary offer price is also primarily determined by the DDM. For 20 out of 22 IPOs $(90.9 \%)$ for which a DDM value is estimated, the estimate is within $15 \%$ of the preliminary offer price, while for only 19 out of 32 IPOs $(59.4 \%)$ the DFCF estimate is within $15 \%$ of the preliminary offer price. For the multiples estimates, the percentage within $15 \%$ is also much lower than for DDM. Furthermore, we find that the multiples valuations for year +1 are consistently closer to the preliminary offer price than the multiples valuations for year 0, again confirming the results based on a comparison with the final offer price. Comparisons of mean absolute errors and mean squared errors lead to the same conclusions.

$* * *$ Table VI about here $* * *$

\section{B. What is the accuracy of the valuation methods used?}

Next, we investigate the accuracy of the valuation methods by comparing the estimated values to the average stock price in the first month of listing. Results are presented in Table VII. Results based on the stock price on post-IPO days $+10,+20$ and +30 are very similar and are therefore not reported in the paper.

\footnotetext{
*** Table VII about here ***
}

DFCF seems to be an unbiased value estimator: the median valuation error is only $2.4 \%$ and not significant (Wilcoxon signed rank test $\mathrm{p}=0.708$ ). DDM on the other hand produces biased estimates of value: the median valuation error is $-11.4 \%$ and significant $(p=0.003)$. If 
the stock market prices IPOs correctly, then DDM tends to underestimate value. The median valuation error for the best multiple is $-9.9 \%$ and also significant $(\mathrm{p}=0.011)$. For most individual multiple valuation methods, we find a negative median valuation error, but this is significant for only two methods: P/E Stock Exchange (year 0) $(\mathrm{p}=0.023)$ and P/CF (year $+1)(p=0.036)$. Of course, for most multiples the sample is very small, which affects the quality of statistical testing.

Again, we use the percentage within $15 \%$, the mean absolute error and the mean squared error to measure the accuracy of the valuation methods. The results suggest that DFCF, DDM and the best multiple have similar accuracy. For each method, about half of the valuations is within $15 \%$ of the average stock price in the first month of listing. The mean absolute errors and the mean squared errors are also very similar, and the mean absolute errors are not significantly different from each other.

It is interesting to compare our results on value accuracy with the valuation accuracies obtained by Kim and Ritter (1999), who investigate the value accuracy of multiples using a sample of 190 US IPOs from 1992 to 1993. They use recent IPOs as comparables, which are chosen with a mechanical algorithm, and comparables chosen by a firm specializing in IPO research. Comparing IPO multiples to the median comparables multiple and a predicted multiple using regressions, they find much lower valuation accuracy than we do. It may seem surprising that objective valuations by academics are less accurate than valuations by lead underwriters. As we have noted in the introduction, value estimates by lead underwriters may be more accurate because they often have better access to information that is useful for valuation, and the post-IPO stock price may be affected by the valuation of the lead underwriter. Moreover, the Belgian IPOs in our sample are mostly mature firms, that are 
comparatively easy to value. It can also be expected that lead underwriters choose to report only valuation results that are appropriate for the type of firm that needs to be valued, while academics report all estimates of the valuation method(s) they investigate.

When we compare the valuation accuracy of the different multiples approaches in Table VII, it is striking that the valuations based on the forecasted earnings and cash flows in year +1 are consistently more accurate than the valuations based on the forecasted current year's earnings and cash flows: this result holds for both the $\mathrm{P} / \mathrm{E}$ and the $\mathrm{P} / \mathrm{CF}$ multiples based on a peer group and for the $\mathrm{P} / \mathrm{E}$ and the $\mathrm{P} / \mathrm{CF}$ multiples based on the $\mathrm{BXS}$, for all three measures of valuation accuracy ${ }^{6}$. Stock market valuations of the IPO shares rely more on forecasted future earnings and cash flow than on current earnings and cash flow.

Again, we also make a pairwise comparison of valuation methods: DFCF, DDM and P/E based on a peer group for year +1 are mutually compared, as well as $\mathrm{P} / \mathrm{E}$ based on a peer group in year 0 and year +1 . The results, which are presented in Table VIII, confirm those of Table VII.

*** Table VIII about here $* * *$

\section{Valuation and underpricing}

We have found that underwriters rely primarily on DDM to determine the offer price. An explanation might be that underwriters believe that DDM produces the most accurate value

\footnotetext{
${ }^{6}$ This result is further confirmed if we take into account valuations based on the earnings and cash flows in years -1 and +2 . We did not include these valuations in Table VII because they are based on a very limited number of observations (1 to 5 observations).
} 
estimates. However, our finding that DDM tends to underestimate value while DFCF is an unbiased value estimator suggests an alternative explanation: underwriters consciously underprice the IPO by relying on a valuation method that tends to underestimate value. This is confirmed by Table IX, which shows that for 20 out of 23 IPOs for which both DDM and DFCF were used, the DDM valuation was lower than the DFCF valuation. For only one IPO DDM and DFCF lead to the same value estimate. This is remarkable, as both valuation methods should yield the same value if consistent assumptions are made.

Another indication that underwriters consciously underprice the IPO is that for 10 of the 27 IPOs for which more than one multiple valuation method was used, the lowest multiple estimate is the 'best multipe': the multiple estimate closest to the offer price (see also Table IX). The highest multiple estimate is the one closest to the offer price for only 4 IPOs. Moreover, for 5 of the 33 IPOs in the sample, the maximum offer price is set lower than all value estimates published in the prospectus. An example is the IPO of Real Software, a Belgian software company: DFCF, minimum multiple and maximum multiple estimates are respectively $13.7 \%, 38.3 \%$ and $40 \%$ higher than the maximum offer price of the IPO, which

is also the final offer price. The average stock price of Real Software in the first month of listing is $53.7 \%$ higher than the maximum offer price.

*** Table IX about here ***

\section{Is the offer price a better predictor of the stock price than pre-IPO value estimates?}

The lead underwriter uses not only value estimation methods but also other information to determine the price at which the shares will be offered to the public (see e.g. Lowry and 
Schwert (2001)). The offer price should therefore be a more accurate predictor of the stock price than the estimates of individual valuation methods. To test whether this is indeed the case, we compare the relation between the offer price and the stock price on the one hand, to the relation between the estimated value and the average stock price in the first month of listing on the other hand. For each valuation approach, the offer price should be closer to the stock price than the value estimate if the lead underwriter also uses other valuable information to determine the price at which the shares will be offered. Results are presented in Table X. As it was found that multiples based on year +1 are consistently more accurate than multiples based on year 0 , this table reports only results of multiple estimates based on year +1 .

*** Table $\mathrm{X}$ about here $* * *$

For the 32 firms that are valued using DFCF, 17 firms (53.1\%) have a DFCF estimated value within $15 \%$ of the stock price, while 20 firms $(62.5 \%)$ have an offer price within $15 \%$ of the stock price. For the 22 firms that are valued using DDM, 12 firms (54.5\%) have a DDM estimated value within $15 \%$ of the stock price, while 15 firms $(68.2 \%)$ have an offer price within $15 \%$ of the stock price. A comparison of mean absolute errors and mean squared errors also suggests that the lead underwriter indeed provides value added by setting the offer price using other information than the DFCF and/or DDM value estimates. However, the differences in the mean absolute errors are never statistically significant ${ }^{7}$.

The results for the multiple estimates in year +1 also generally confirm that the offer price is closer to the stock price than individual valuation estimates, but again, none of the differences

\footnotetext{
${ }^{7}$ t-values are 0.08 for DFCF, 0.34 for DDM, 0.63 for P/E Peer Group (year +1 ), 0.84 for P/E Stock Exchange (year +1$), 0.70$ for P/CF Peer Group (year +1$)$ and 0.09 for P/CF Stock Exchange (year +1$)$.
} 
in the mean absolute errors are statistically significant. For the $\mathrm{P} / \mathrm{CF}$ multiples, the results are mixed, but the available number of observations is too small to draw conclusions.

Overall, the figures in Table $\mathrm{X}$ indicate that the offer price is closer than the pre-IPO value estimates of the lead underwriter, but this is not confirmed by the statistical tests.

\section{Conclusions}

There have been several studies that investigate the accuracy of valuation approaches using ex post value estimates, but to our knowledge we are the first to investigate the accuracy of valuation by practitioners. We investigate the valuation by the lead underwriters of 33 IPOs on the BXS in the 1993-2000 period. We find that the lead underwriter always uses several valuation approaches, of which DFCF is the most popular. The offer price seems to be mainly driven by the DDM if applied. However, we find that DDM is neither better nor worse in predicting market value than other valuation approaches. Moreover, our results suggest that DDM tends to underestimate value, while DFCF produces unbiased value estimates, which indicates that underwriters consciously underprice the IPO by relying on a valuation method that tends to underestimate value.

When multiples valuation is used, investment banks rely mostly on forecasted future earnings and cash flows. We find that multiples valuation based on post-IPO forecasted earnings and cash flows indeed leads to more accurate valuations than multiples valuation based on earnings and cash flows in the IPO-year. Our results also indicate that the IPO offer price is closer to the post-IPO stock price than the estimates of individual valuation methods, which is 
consistent with the lead underwriter using not only value estimates but also other valuable information to set the offer price.

The accuracy of the valuations by Belgian investment banks may seem remarkable when compared to the valuation accuracy obtained in other papers. However, it has to be taken into account that firms that go public in Belgium are generally mature, profitable firms, that are easier to value than young high growth firms. Moreover, lead underwriters will often have access to much more information which is useful for valuation than outsiders, and the lead underwriter may choose to report only valuation results that are appropriate for the type of firm that needs to be valued. 


\section{References}

Alford A.W., 1992, "The effect of the set of comparable firms on the accuracy of the priceearnings valuation method", Journal of Accounting Research 30 (1), 94-108.

Berkman, H., M.E. Bradbury and J. Ferguson, 2000, "The accuracy of price-earnings and discounted cash flow methods of IPO equity valuation", Journal of International Financial Management and Accounting 11 (2), 71-83.

DeAngelo L.E., 1990, "Equity valuation and corporate control”, Accounting Review 65 (1), 93-112.

Fernandez, P., 2001, "Internet valuations: The case of Terra-Lycos", Working Paper, IESE Business School.

Gilson, S.C., E.S. Hotchkiss and R.S. Ruback, 2000, "Valuation of bankrupt firms", Review of Financial Studies 13 (1), 43-74.

Kaplan, S.N. and R.S. Ruback, 1995, "The valuation of cash flow forecasts: An empirical analysis", Journal of Finance 50 (4), 1059- 1093.

Kim, M. and J.R. Ritter, 1999, "Valuing IPOs”, Journal of Financial Economics 53, 409-437.

Lowry, M. and G.W. Schwert, 2001, "Biases in the IPO pricing process", Working Paper, Penn State University.

Pagano M., F. Panetta and L. Zingales, 1998, "Why do companies go public? An empirical analysis", Journal of Finance 53 (1), 27-64.

Rydqvist, K. and K. Högholm, 1995, “Going public in the 1980s: Evidence from Sweden”, European Financial Management 1 (3), 287-315. 
Table I

Distribution across industries -

33 Belgian IPOs (1993-2000)

\begin{tabular}{lc}
\hline \hline \multicolumn{1}{c}{ Industry } & $\begin{array}{c}\text { Number } \\
\text { of IPOs }\end{array}$ \\
\hline Construction & 1 \\
Textiles & 3 \\
Distributors & 1 \\
Retailers & 2 \\
Entertainment & 1 \\
Publishing & 1 \\
Restaurants & 2 \\
Electronic \& electric equipment & 2 \\
Engineering & 3 \\
Computer hardware & 1 \\
Software \& computer services & 6 \\
Beverages & 3 \\
Food producers \& processors & 2 \\
Medical equipment & 1 \\
Packaging & 2 \\
Personal care \& household products & 1 \\
Gas distribution & 1 \\
\hline
\end{tabular}


Table II

Descriptive statistics - 33 Belgian IPOs (1993-2000)

\begin{tabular}{cccccc}
\hline \hline & Mean & St. dev. & Minimum & Median & Maximum \\
\hline \% of shares offered to the public $\left(^{*}\right)\left(^{* *}\right)$ & 33.4 & 13.8 & 13.9 & 35.3 & 63.7 \\
Offer price $(\mathrm{BEF})\left(^{*}\right)$ & 58 & 117 & 22 & 36 & 694 \\
Average price in the first month of listing $(\mathrm{BEF})$ & 65 & 116 & 22 & 40 & 696 \\
Initial return $(\%)\left({ }^{*}\right)\left({ }^{* * *}\right)$ & 18.9 & 35.3 & -19.3 & 10.3 & 166.3 \\
\hline Only existing shares & Number of firms offering $\left(^{*}\right):$ & & \\
Existing shares and new shares & 8 & & & \\
Only new shares & 21 & & & \\
\end{tabular}

Notes: $\left({ }^{*}\right)$ Information not available for 1 observation; $\left({ }^{* *}\right)$ green shoe option not included; $\left({ }^{* * *}\right)$ initial return $=$ [average price in the first month of listing / offer price] - 1. 
Table III

Valuation methods used by lead underwriters of 33 Belgian IPOs (1993-2000)

\begin{tabular}{lc}
\hline \hline \multicolumn{1}{c}{ Valuation method } & $\begin{array}{c}\text { Number } \\
\text { of IPOs }\end{array}$ \\
\hline Discounted free cash flow & 33 \\
Dividend discount model & 23 \\
Multiples & 31 \\
- Price/earnings & 30 \\
$\quad$ Peer group & 28 \\
Brussels stock exchange & 14 \\
$\quad$ Growth shares & 3 \\
- Price/cash flow & 19 \\
$\quad$ Peer group & 17 \\
$\quad$ Brussels stock exchange & 9 \\
$\quad$ Growth shares & 2 \\
- EnterpriseValue/EBIT(DA) $(*)$ & 8 \\
- (peer group) & 3 \\
$\quad$ EnterpriseValue/sales & 2 \\
$\quad$ Peer group & 1 \\
- Brussels stock exchange & 1 \\
Price/book (peer group) & 2 \\
Dividend yield (peer group) & 1 \\
\hline P/E-to-growth (peer group) & \\
\hline Notes: All IPOs for which the application of a valuation \\
method is mentioned in the prospectus are included, \\
irrespective of whether the prospectus provides a value \\
estimation or not. (*) In two cases Equity/EBIT instead \\
of Equity/EBITDA is used
\end{tabular}




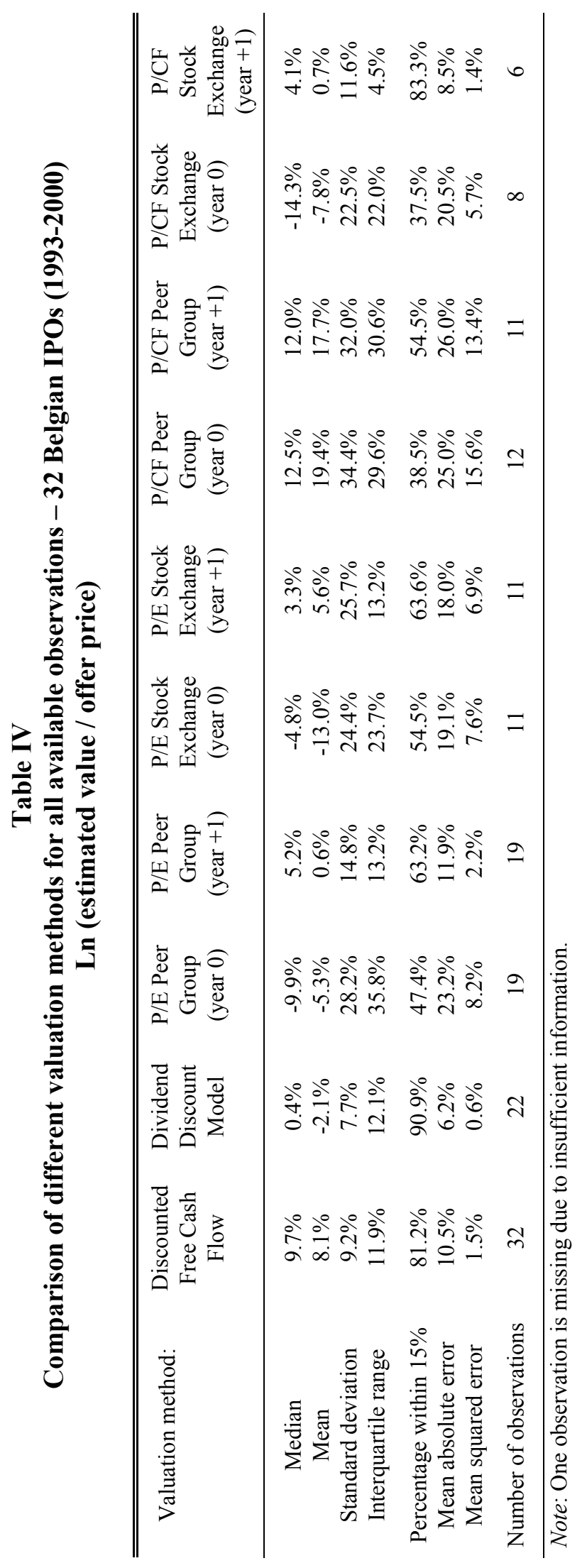

n 


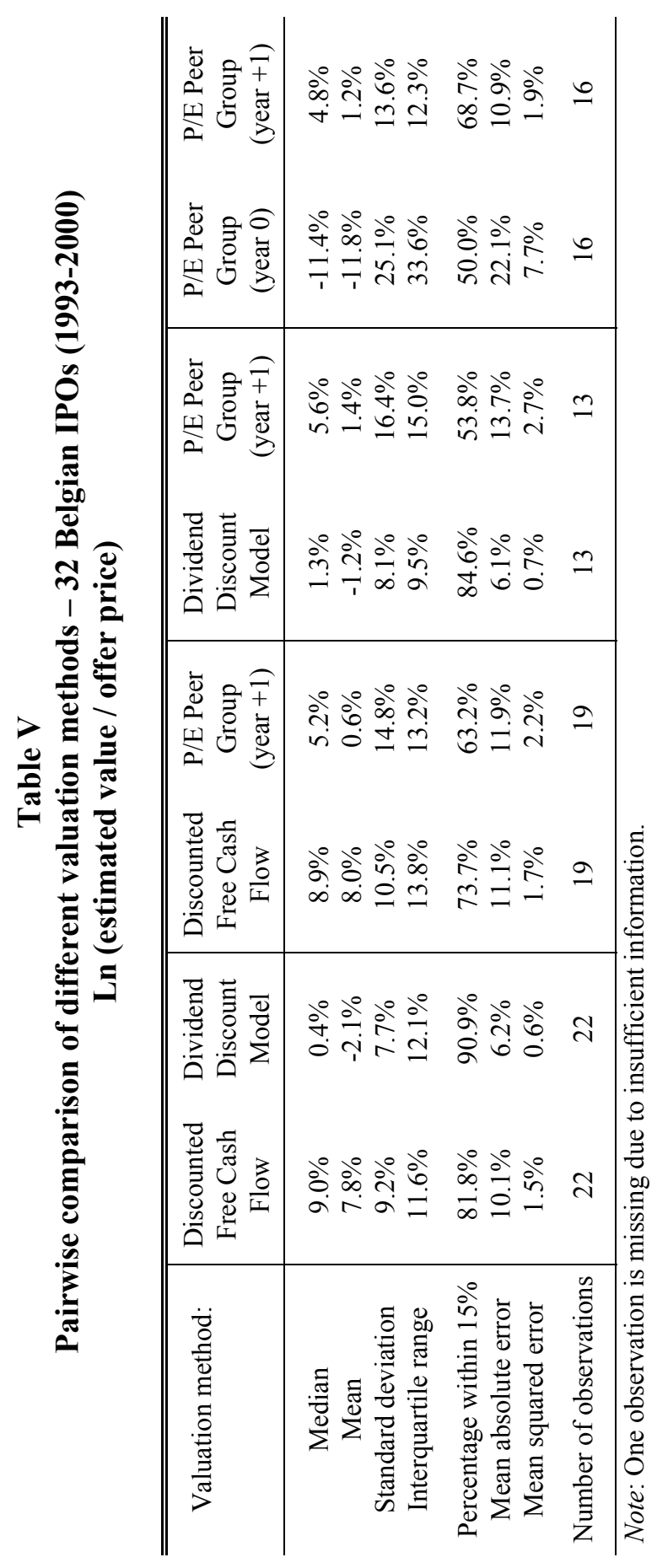

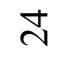




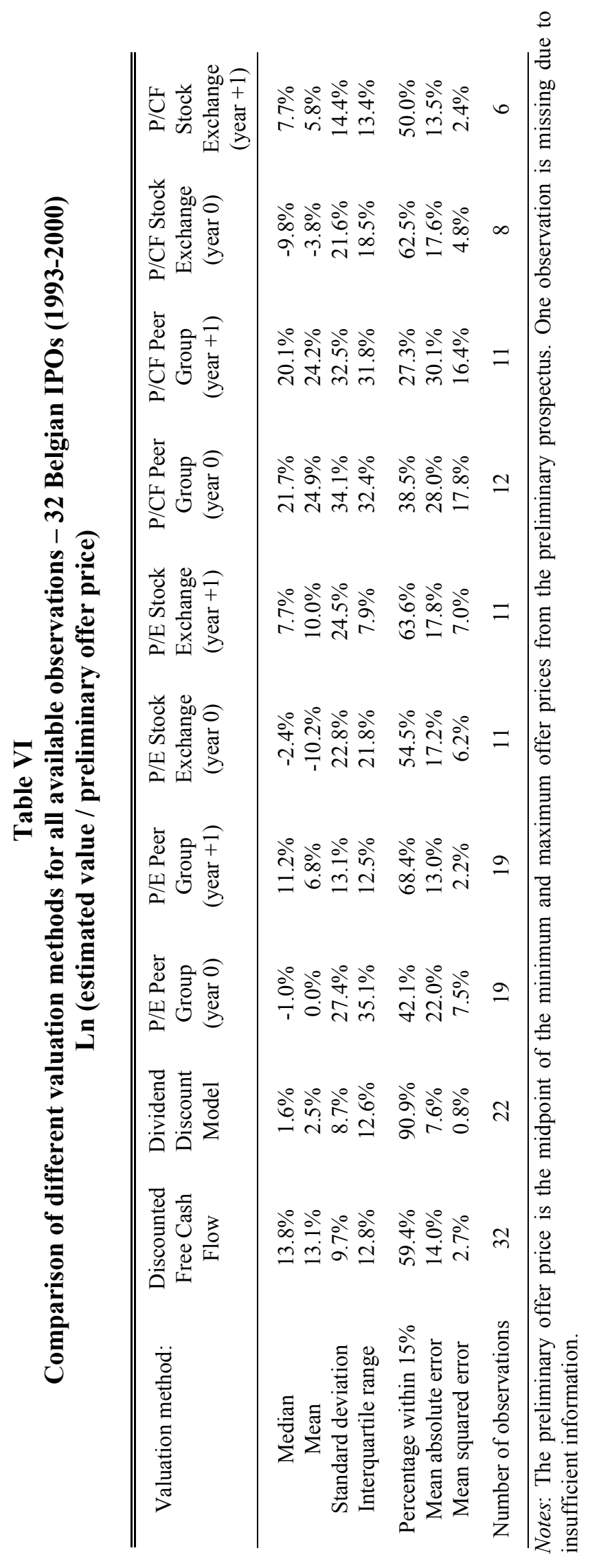




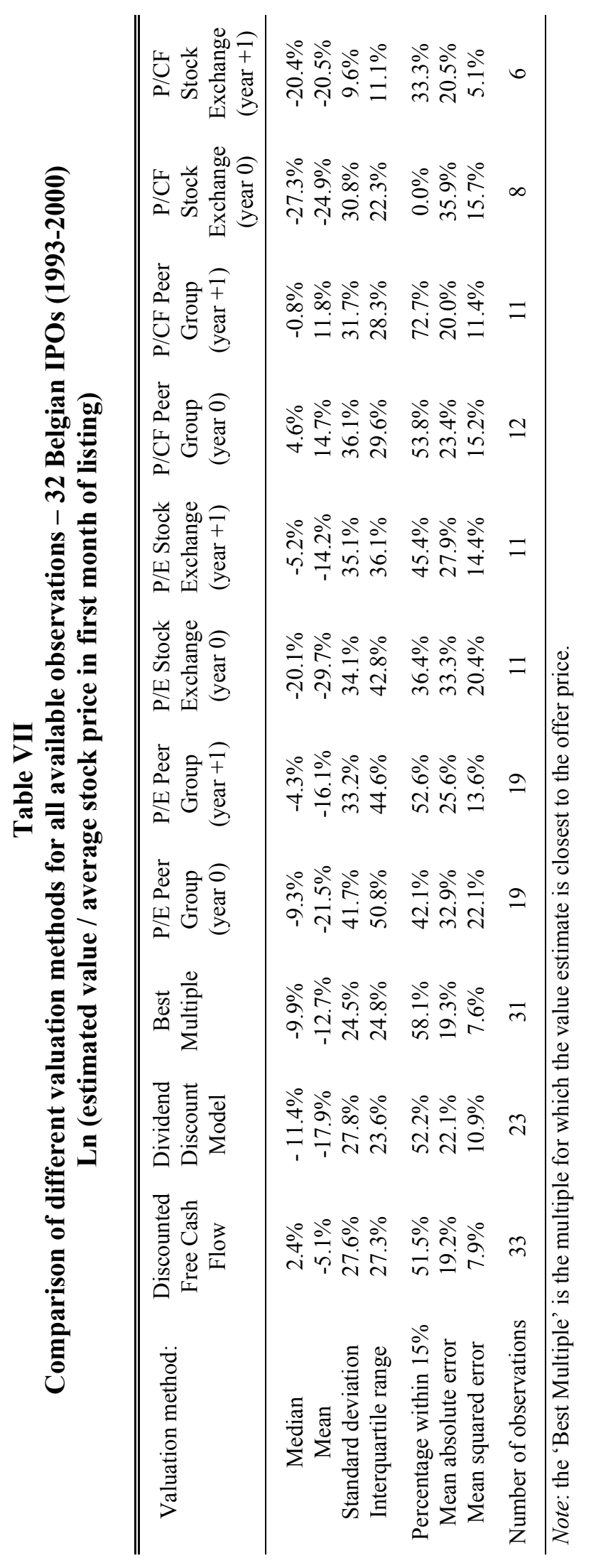

ำ 


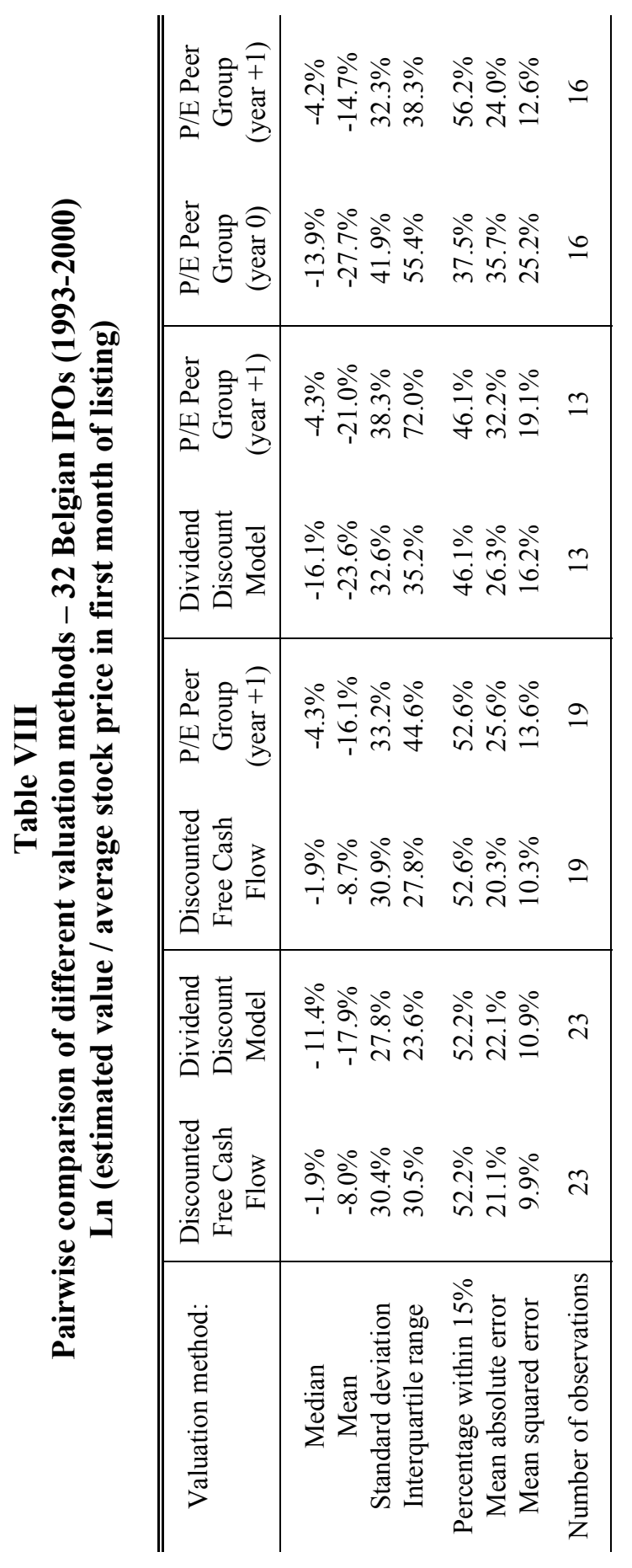

N 


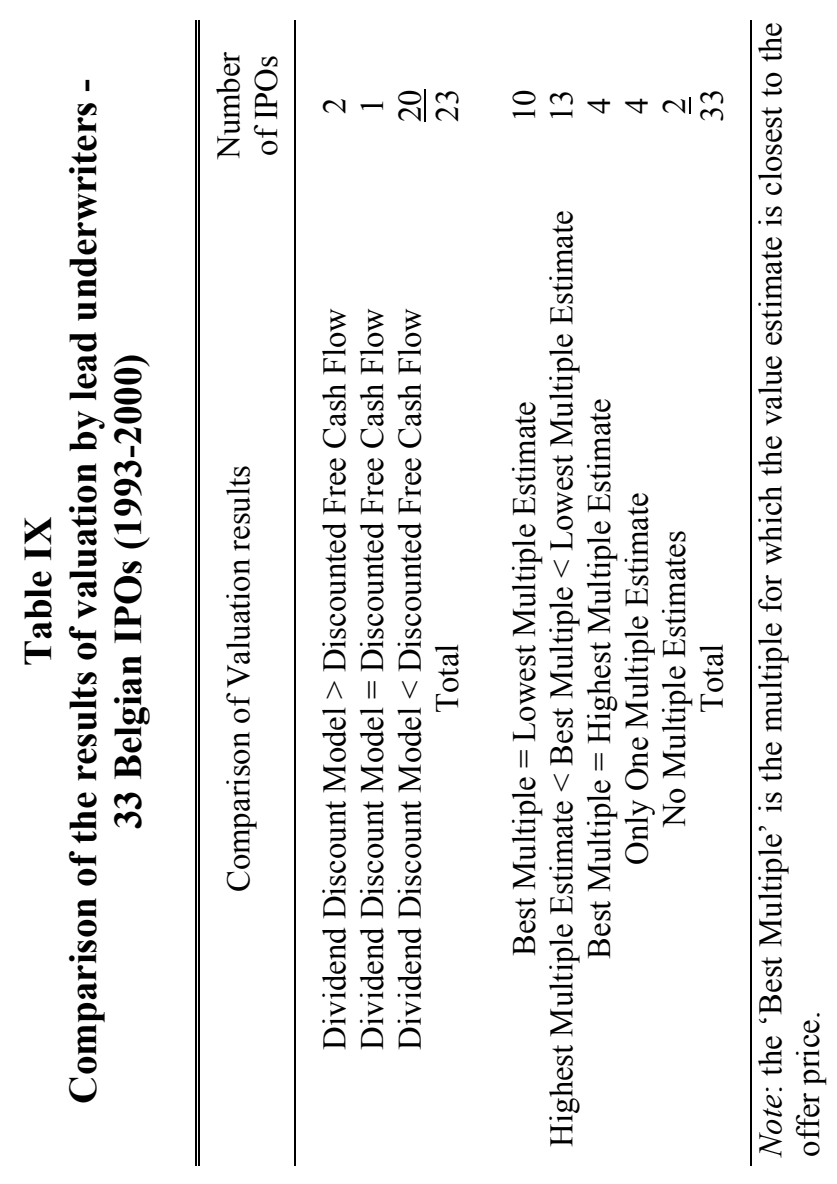

$\stackrel{\infty}{\sim}$ 


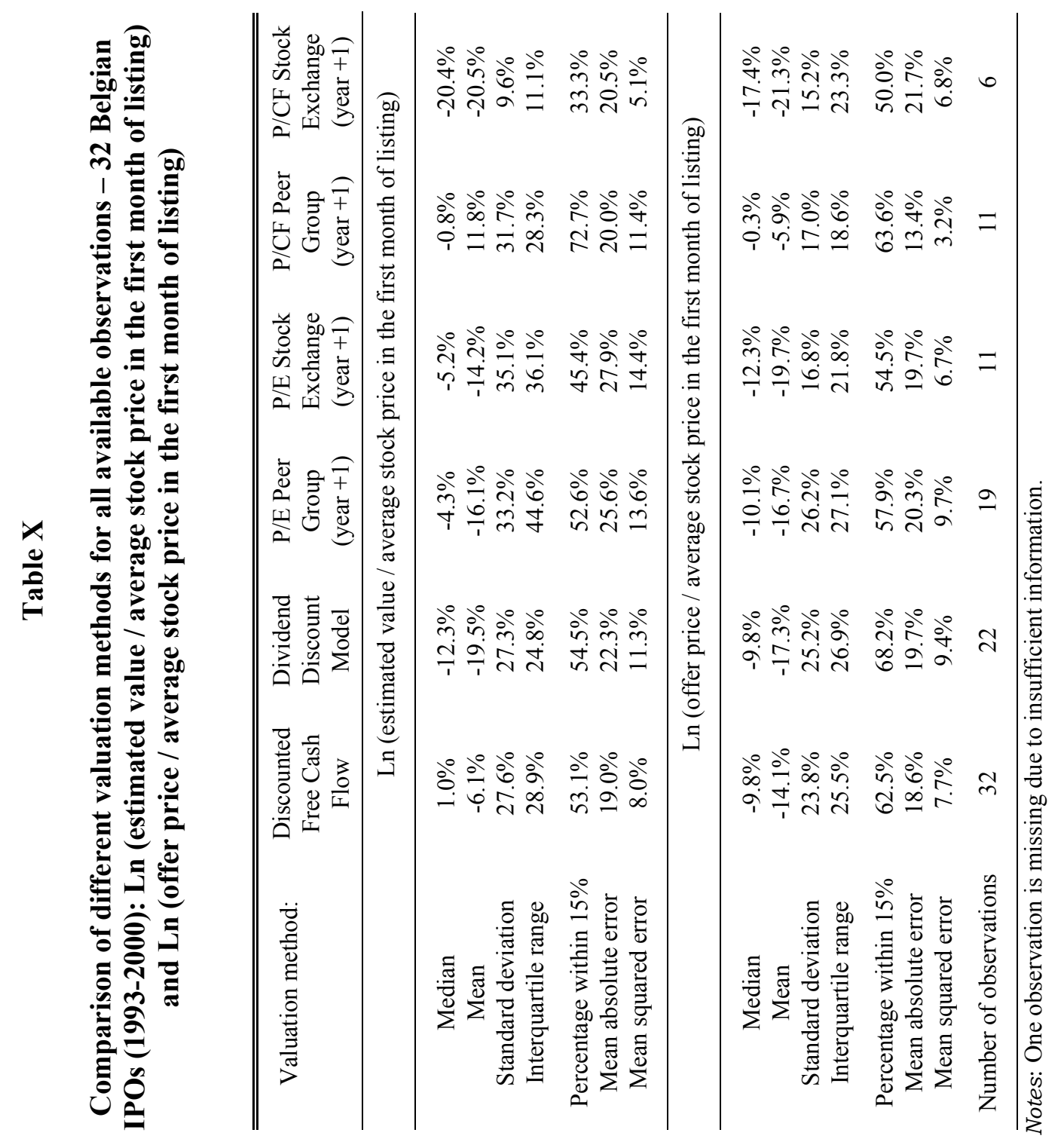

กิ 